\title{
Knowledge, attitude and willingness to accept the RTS,S malaria vaccine among mothers in Abuja, Nigeria
}

\author{
Tolulope Musa-Booth, ${ }^{1}$ Blessing Enobun, ${ }^{2}$ Adewumi Agbomola, ${ }^{3}$ Clive Shiff ${ }^{1}$ \\ ${ }^{1}$ Department of Molecular Microbiology and Immunology, Johns Hopkins Bloomberg School of Public \\ Health, Baltimore, USA; ${ }^{2}$ University of Maryland, Baltimore, USA; ${ }^{3}$ National Malaria Elimination \\ Programme, Abuja, Nigeria
}

\author{
Correspondence: Tolulope Musa-Booth, Department of Molecular \\ Microbiology and Immunology, Johns Hopkins Bloomberg School of \\ Public Health, 615 N. Wolfe St, 21205 Baltimore, MD, USA. \\ Tel.: +14438151957 \\ E-mail: toluonile2@gmail.com
}

Keywords: Knowledge; attitude; malaria prevention; RTS,S malaria vaccine; vaccine acceptance.

Acknowledgements: We acknowledge the respondents who participated in the study. We also acknowledge the contribution of the data collectors, health workers at the public secondary health facilities, and FCT hospital management board. We want to thank the Johns Hopkins Bloomberg School of Public Health (JHSPH) Institutional Review Board (IRB) and the FCT Health Research Ethics Committee for granting approval to conduct this study.

Contributions: TOM conceived the study, designed the study, coordinated data collection and drafted the manuscript; AJA was involved in training of survey personnel and supervision of data collection; BEE analyzed the data and participated in drafting the manuscript; CJS advised on how to conduct the study, draft the manuscript, served as the principal investigator and reviewed the final manuscript. All authors read and approved the final manuscript.

Conflict of interest: The authors declare no conflict of interest.

Funding: The Master Public Health program Johns Hopkins Bloomberg School of Public Health supported the conduct of this study by awarding the JB grant to TOM to fund data collection.

Availability of data and materials: All data generated or analyzed during this study are included in this published article.

Ethics approval and consent to participate: Ethical approval was obtained from Johns Hopkins Bloomberg School of Public Health (JHSPH) Institutional Review Board (IRB) and the FCT Health Research Ethics Committee prior to administration of the questionnaire. The Chief Medical Directors of the secondary health facilities visited were subsequently notified and the data collection tool pre-tested before data collection commenced.

Informed consent: Written informed consent was obtained from a legally authorized representative(s) for anonymized patient information to be published in this article.

Further information: Manuscript preprint is on MedRxiv: https://medrxiv.org/cgi/content/short/2020.12.03.20242784v1

Received for publication: 24 September 2020.

Revision received: 12 February 2021.

Accepted for publication: 17 June 2021.

This work is licensed under a Creative Commons Attribution NonCommercial 4.0 License (CC BY-NC 4.0).

CCopyright: the Author(s),2021

Licensee PAGEPress, Italy

Annals of African Medical Research 2021; 4:128

doi:10.4081/aamr.2021.128

\begin{abstract}
Malaria constitutes a major public health challenge and Nigeria contributes hugely to the global burden. In recent times, there has been a massive scale up of all interventions for evident impact. One of the novel preventive measures being considered is the RTS,S malaria vaccine. The objective of this study was to assess mothers' knowledge, attitude, and practices to malaria and its prevention as well as mothers' willingness to accept the RTS,S/AS01 malaria vaccine. A cross-sectional study design was used to administer questionnaires to 180 mothers within six public secondary health facilities in Abuja, Nigeria. About 30\% (36/180) of respondents were aware of malaria vaccines but only four percent $(7 / 180)$ had heard of RTS,S. Young maternal age (OR, 2.4; 95\% CI, 1.09-5.28; $\mathrm{P}=0.03$ ), self-employment (OR, 2.55; 95\% CI, 1.04-6.28; $\mathrm{P}=0.04)$ and formal employment $(\mathrm{OR}, 3.74 ; 95 \% \mathrm{CI}$, $1.17-11.99 ; \mathrm{P}=0.03$ ) were associated with no prior knowledge of malaria vaccine. Ninety-one percent $(163 / 180)$ had a positive attitude to malaria vaccine and $98 \%(176 / 180)$ were willing to allow their child(ren) to be immunized with RTS,S despite the efficacy of the vaccine, route of administration and number of doses. We concluded that knowledge of malaria preventive measures does not correlate with knowledge of RTS,S. Although willingness to accept RTS,S is high, consistent targeted messaging on RTS,S would be required to improve community knowledge and attitude prior to implementation to ensure maximum uptake.
\end{abstract}

\section{Introduction}

Malaria, although discovered over a century ago, continues to be of public health significance because of its huge global burden making it a leading cause of disease and death worldwide. Most recent estimates of global malaria cases stand at 229 million as of 2019. ${ }^{1,2}$ This is one million more cases than the previous year while malaria claimed over 400000 lives with majority (94\%) of cases and deaths occurring in Africa. ${ }^{1,2}$ There was no significant reduction in malaria cases recorded from 2015-2017 despite the investments and interventions in place to control malaria globally. Although the 2020 world malaria report shows that there was a reduction in the number of deaths in the high burden to high impact countries, there was still an increase in the number of cases ${ }^{1-4}$ and more has to be done to achieve the set goals for control and elimination.

Nigeria is malaria endemic and accounts for a quarter of the global burden. ${ }^{3}$ It also reported an increase in malaria cases in 2019 and accounted for $23 \%$ of all global malaria deaths. ${ }^{1,3}$

The last National Malaria Indicator Survey (NMIS) done in Nigeria indicated Plasmodium falciparum malaria accounts for majority of outpatient visits $(60 \%)$ and admissions $(30 \%)$. 5,6 This has remained unchanged over the years as the disease also con- 
tributes about $11 \%$ of maternal mortality, $25 \%$ of infant mortality, and $30 \%$ of under-5 mortality. ${ }^{5,6}$ Approximately 110 million clinically diagnosed cases of malaria and nearly 300,000 malaria-related childhood deaths occur each year in Nigeria. ${ }^{5,6}$ Malaria remains a major public health problem in Nigeria, weakening the health system and causing annual economic Gross Domestic Product (GDP) losses of about $40 \%$, about 480 billion naira in out-of-pocket treatments, prevention costs, and loss of man hours. ${ }^{5}$ Fluctuation in malaria control and elimination investments over the years has led to a widening gap between amount invested and amount needed. ${ }^{1}$ Following the usual trend, nearly three quarters of the 3.0 billion U.S. dollars invested in malaria control and elimination globally in 2019 was spent in the World Health Organizations (WHO) Africa region. ${ }^{1}$

To meet the WHO global technical strategy targets ${ }^{7}$ and the sustainable development goal $3.3,{ }^{8}$ more funding will be required for research, and development of malaria vaccines in addition to the interventions currently in place. With the coronavirus disease 2019 (COVID-19) pandemic taking a toll on health systems worldwide, it will be a challenge to achieve the set targets for malaria control and elimination but with the rising number of cases and deaths, vaccine science has been brought to the fore. Approximately 20 P. falciparum malaria vaccine candidates are either at advanced preclinical or clinical stages of development but only RTS,S/AS01 vaccine, has passed phase III clinical trial. ${ }^{9}$ Results showed that the vaccine was effective especially when used in conjunction with other preventive measures. ${ }^{10,11} \mathrm{~A}$ pilot implementation study was subsequently recommended by WHO and is ongoing in Ghana, Malawi and Kenya to evaluate how four doses of RTS,S can be implemented among five to 17 month old children at first dose and the risk/benefits of the vaccine. ${ }^{10}$

There is very little data on the knowledge, attitude and practices of Nigerians or any society, to the potential RTS,S malaria vaccine. A study done in Ibadan, southwest Nigeria revealed that only $20 \%$ of caregivers had heard of malaria vaccine. ${ }^{12}$ Although approximately $87 \%$ were willing to accept a malaria vaccine, almost $50 \%$ of the caregivers did not think it would be accepted if it was not given orally. ${ }^{12}$ Another study done in Owerri west, southeast Nigeria showed approximately $48 \%$ knowledge of malaria vaccine, $88.2 \%$ positive perception and $95.6 \%$ willingness to accept the vaccine. ${ }^{13}$ Our structured study represents a cross section of maternal population in the city of Abuja, north central Nigeria to assess their knowledge, attitude, and practices to malaria and its prevention as well as mothers' willingness to accept the RTS,S/AS01 malaria vaccine.

\section{Materials and Methods \\ Study Design}

A cross sectional study design was adopted. Knowledge, attitude and practices of mothers to malaria, malaria prevention and RTS,S vaccine were assessed. Mothers' willingness to allow their children to receive RTS,S vaccine was assessed as well as mothers' sociodemographic characteristics.

\section{Study Setting}

The study was conducted in the federal capital territory, Abuja, Nigeria, which is in the North-Central part of Nigeria within latitude $745^{\prime}$ and $739^{\prime} .{ }^{14}$ It is the legislative capital of Nigeria with a vastly diverse population. The population of Abuja in 2019 is estimated to be $3,095,118$ with a growth rate of $6.11 \%$, making it one of the fastest growing cities in the world. ${ }^{15}$ About half the population are Muslims and Christians make up approximately $40 \%$ of the population. The official language is English although other languages are spoken in the city including Hausa, Igbo, and Yoruba. ${ }^{15}$

\section{Participants}

Consenting mothers between ages 15-49 years with children below 17 months who attended well baby clinics were interviewed in six public secondary health facilities within Abuja Municipal Area Council which has the largest population.

\section{Sampling}

Sample size was determined to be 157 mothers using Leslie Kish formula with a prevalence rate of $45 \%$ (obtained from Nigeria MIS 2015), confidence interval of 0.01 , confidence level of $95 \%$. With a $10 \%$ non-response (attrition) rate added to the sample size, the number of respondents required was 173 .

A multistage sampling technique was used to select respondents from the health facilities visited. The Federal Capital Territory (FCT) was divided into six clusters representing the area council districts - Abuja Municipal (AMAC), Abaji, Gwagwalada, Kuje, Bwari and Kwali. The area council with the highest population (AMAC) was selected. Health facilities were then stratified into primary, secondary, and tertiary facilities and secondary health facilities were visited. The secondary health facilities were further stratified into public and private facilities. Well baby clinics in six public secondary health facilities within Abuja (Figure 1) were subsequently visited and mothers between the ages of 15-49 years with children below 17 months who gave consent were interviewed.

\section{Study Tool}

A pre-tested semi-structured interviewer-administered questionnaire was used to collect information from respondents. Prior to administration of questions on practices and willingness to accept RTS,S, malaria vaccine, mothers were given information on RTS,S so that well-informed responses would be obtained.

\section{Data Collection}

Prior to data collection, interviewers, supervisors, coordinators

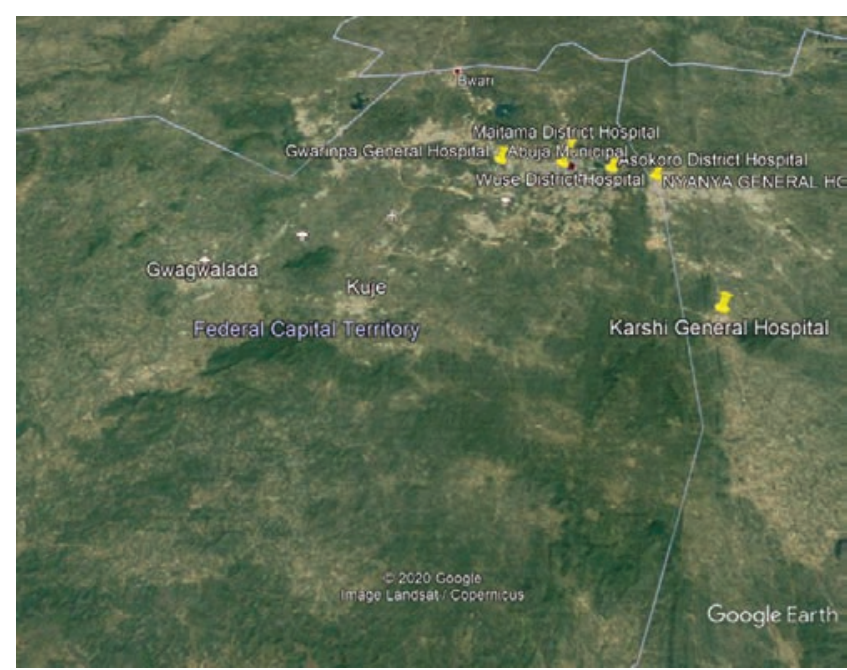

Figure 1. Geospatial map of public secondary health facilities in AMAC. 
and recruitment personnel were trained on human subject research ethics, the study protocol, how to conduct advocacy at the health facilities and appropriate ways to approach the respondents. The study was conducted between February and March 2020. Questionnaires were administered to 180 consenting mothers.

\section{Data Analysis}

Data were analyzed using Stata/MP 15.0 (StataCorp. 2017. Stata Statistical Software: Release 15. College Station, TX: StataCorp LLC). Descriptive statistics were used to summarize the socio-demographic characteristics. Mean and standard deviation were employed to summarize continuous data. Counts and percentages were utilized to summarize categorical variables. Potential predictors (independent variables) were assessed for a statistical association with the outcome variables (the dependent variables) using univariate and multivariable logarithmic regression analysis with inclusion of 0.10 .

\section{Ethical considerations}

Ethical approval was obtained from Johns Hopkins Bloomberg School of Public Health (JHSPH) Institutional Review Board (IRB) and the FCT Health Research Ethics Committee prior to administration of the questionnaire. The Chief Medical Directors of the secondary health facilities visited were subsequently notified and the data collection tool pre-tested before data collection commenced. Information on the nature of the survey was given to respondents and signed written informed consent was obtained from every mother participating in the study before administration of the questionnaire. Privacy and confidentiality were also maintained throughout the process of data collection.

\section{Outcome variables}

Knowledge of malaria preventives measures was coded as a dichotomous variable: less than three preventive measures vs three or more preventive measures, to assess mothers' knowledge on malaria prevention. Knowledge of the malaria vaccine was measured as a dichotomous variable: yes or no. Mothers' attitude to malaria, its prevention and malaria vaccine was assessed using a malaria attitude score. The malaria attitude score was a sum of the Likert scale values of the six questions on attitude in section D of the questionnaire. The scoring on the Likert scale for three questions (avoid contact with someone who has malaria, not immunized with malaria vaccine and immunization with malaria vaccine) were reversed to tally positively with the other three questions. The minimum malaria attitude score a respondent could attain was six points and the maximum was 30 points. A cut-off of 24 points was selected as the threshold, which corresponds to a score of four on each of the six questions on attitude. A score of 24 points and above represented good attitude and a score below 24 points, poor attitude on malaria and malaria prevention. Mothers' practices regarding malaria vaccination were measured by willingness to allow child to be immunized with malaria vaccine, bring child for vaccination, immunize child by injection and use of other preventive measures after vaccination. All four outcomes were dichotomized as yes, no responses.

\section{Results}

\section{Socio-demographic characteristics}

The average age of respondents was 30 years with a vast majority of mothers being married (96\%), 58\% of respondents had post-secondary education and a little over half of the respondents were self-employed (54\%). Mothers were predominantly Christian $(86 \%)$ and the three main ethnic groups were well represented although Igbos made up the majority of respondents (24\%). Some of the other tribes captured include Idoma, Igala and Edo (Table 1).

\section{Knowledge of malaria, its prevention and RTS,S vaccine}

All (180/180) respondents had heard of malaria, $81 \%$ (145/180) of respondents knew mosquito bite causes malaria, 59\% (124/180) knew one or two malaria preventive measures and $94 \%$ $(170 / 180)$ knew everyone is at risk of infection. Twenty-eight (28) of $180(16 \%)$ respondents had not seen any message nor received any training on malaria, $46 \%(82 / 180)$ saw messages or received training on malaria from one or two sources, $31 \%(56 / 180)$, three to five sources and seven percent (12/180), more than five sources. Majority of respondents $(92 \% ; 166 / 180)$ knew malaria could be fatal if untreated, however, only $30 \%(36 / 180)$ of respondents were aware of malaria vaccines. Five percent $(8 / 180)$ knew what a malaria vaccine was used for and only four percent (7/180) had heard of RTS,S. Multivariable logistic regression analyses indicated ethnicity, education and number of messages or training on malaria were associated with mother's knowledge of three or more preventive measures against malaria. Igbos and other ethnic groups were $70 \%$ less likely (OR, $0.27 ; 95 \% \mathrm{CI}, 0.08-0.87 ; \mathrm{P}=0.03$; and OR, $0.27 ; 95 \% \mathrm{CI}, 0.10-0.77 ; \mathrm{P}=0.01$ respectively) to know three or more preventive measures against malaria compared with Hausas and Yorubas. Post-secondary respondents compared with

Table 1. Socio-demographic characteristics of respondents.

\begin{tabular}{lc} 
Characteristics & Respondents (N=180) \\
Age (years) & $n=179$ \\
Min-Max & $16-49$ \\
Mean (SD) & $30(5.6)$ \\
Marital Status n (\%) & \\
Single & $7(4)$ \\
Married & $173(96)$ \\
\hline Religion n (\%) & \\
Christianity & $154(86)$ \\
Islam & $26(14)$ \\
Traditional & $0(0)$ \\
Ethnicity n (\%) & \\
Hausa & $30(17)$ \\
Igbo & $44(24)$ \\
Yoruba & $22(12)$ \\
Other & $84(47)$ \\
\hline Education*n (\%) & \\
Pre-secondary & $6(3)$ \\
Secondary & $67(37)$ \\
Post-secondary & $103(58)$ \\
Other & $3(2)$ \\
Employment status & $\mathrm{n}=179$ \\
Not employed & $37(21)$ \\
Self-employed & $96(54)$ \\
Formally employed & $42(23)$ \\
Other & $4(2)$ \\
\hline
\end{tabular}

*education: pre-secondary includes primary and no formal education, post-secondary includes professional degrees, post graduate diploma, bachelors, or higher education. 
pre-secondary respondents were $87 \%$ less likely (OR, $0.13 ; 95 \%$ CI, 0.02-0.90; $\mathrm{P}=0.04$ ) to know at least three malaria preventive measures. There was marginal significance in the knowledge of at least three malaria preventive measures between respondents who have attained secondary (OR, $0.16 ; 95 \% \mathrm{CI}, 0.02-1.11, \mathrm{P}=0.07)$ or other educational status (OR, 0.04; 95\% CI, 0.001-1.13; $\mathrm{P}=0.06$ ) compared with those with pre-secondary education. Respondents who had seen or received at least three messages and training on malaria were 8.2 times more likely to be aware of at least three malaria preventive measures $(95 \%$ CI, 3.77-18.0, $\mathrm{P}<0.001$; Table 2 ). Respondents 30 years and younger were more than two times more likely to be unaware of the existence of a malaria vaccine compared with older respondents (OR, 2.40; 95\% CI, 1.09-5.28; $\mathrm{P}=0.03)$. Compared with unemployed respondents, self-employed (OR, 2.55; 95\% CI 1.04-6.28; $\mathrm{P}=0.04)$ and formally employed respondents (OR, 3.74; 95\% CI 1.17-11.99, $\mathrm{P}=0.03)$ were more than two times more likely to have no prior knowledge of malaria vaccine (Table 3 ).

Table 2. Factors associated with mother's knowledge of three or more malaria preventive measures.

$\begin{array}{lccc} & \begin{array}{c}\text { Univariate models } \\ \text { OR }(95 \% \text { CI) }\end{array} & \text { P } & \text { Multivariable model } \\ \text { OR (95\% CI) }\end{array}$

$\mathrm{OR}$, odds ratio; $\mathrm{CI}$, confidence interval

Table 3. Factors associated with no prior knowledge of malaria vaccine.

\begin{tabular}{|c|c|c|c|c|}
\hline & $\begin{array}{l}\text { Univariate models } \\
\text { OR }(95 \% \mathrm{CI})\end{array}$ & p & $\begin{array}{l}\text { Multivariable model } \\
\text { OR }(95 \% \text { CI) }\end{array}$ & p \\
\hline $\begin{array}{l}\text { Age (years) } \\
\quad \leq 30 \\
\quad>30\end{array}$ & $\begin{array}{c}2.20(1.51-4.65) \\
\text { Reference }(1.00)\end{array}$ & 0.04 & $\begin{array}{c}2.40(1.09-5.28) \\
\text { Reference (1.00) }\end{array}$ & 0.03 \\
\hline $\begin{array}{l}\text { Ethnicity } \\
\text { Hausa } \\
\text { Igbo } \\
\text { Yoruba } \\
\text { Other } \\
\end{array}$ & $\begin{array}{c}\text { Reference }(1.00) \\
0.81(0.28-2.38) \\
0.65(0.19-2.24) \\
2.25(0.77-6.59) \\
\end{array}$ & $\begin{array}{l}0.70 \\
0.50 \\
0.14\end{array}$ & - & - \\
\hline $\begin{array}{l}\text { Education } \\
\text { Pre-secondary } \\
\text { Secondary } \\
\text { Post-secondary }\end{array}$ & $\begin{array}{c}\text { Reference }(1.00) \\
0.69(0.08-6.40) \\
0.83(0.09-7.50)\end{array}$ & $\begin{array}{l}- \\
0.75 \\
0.89\end{array}$ & - & \\
\hline $\begin{array}{l}\text { Other } \\
\text { Employment status } \\
\text { Not employed } \\
\text { Self-employed } \\
\text { Formally employed } \\
\text { Other }\end{array}$ & $\begin{array}{c}- \\
\text { Reference }(1.00) \\
2.23(0.94-5.30) \\
2.88(0.95-8.69) \\
1.44(0.14-15.33)\end{array}$ & $\begin{array}{l}0.07 \\
0.06 \\
0.76\end{array}$ & $\begin{array}{c}\text { Reference }(1.00) \\
2.55(1.04-6.28) \\
3.74(1.17-11.99) \\
1.94(0.17-22.59)\end{array}$ & $\begin{array}{l}0.04 \\
0.03 \\
0.60\end{array}$ \\
\hline $\begin{array}{l}\text { Message or training on malaria } \\
\quad<3 \text { sources } \\
\geq 3 \text { sources }\end{array}$ & $\begin{array}{c}0.07 \\
\text { Reference }(1.00) \\
2.13(0.93-4.87)\end{array}$ & 0.12 & $\begin{array}{c}\text { Reference }(1.00) \\
1.97(0.84-4.61)\end{array}$ & \\
\hline
\end{tabular}

$\mathrm{OR}$, odds ratio; $\mathrm{CI}$, confidence interval 


\section{Attitude to malaria, its prevention and RTS,S vaccine}

Majority of mothers $(89 \% ; 160$ of 180$)$ agreed or strongly agreed that malaria was a serious and life-threatening disease. 91\% (163 of 180) of respondents agreed or strongly agreed that sleeping inside a mosquito net was one way to prevent malaria, 91\% (163 of 180) also agreed or strongly agreed that vaccines are important in managing malaria and $21 \%$ (38 of 180) disagreed or strongly disagreed that immunization with malaria vaccine provide lifelong protection from malaria. 159 respondents $(88 \%)$ disagreed or strongly disagreed that close contact with someone who had malaria should be avoided and $81 \%$ (146 of 180) also disagreed or strongly disagreed that anyone not immunized with malaria vaccine should be avoided.

There was zero percent floor and ceiling effects on the malaria attitude scale. Multivariable logistic regression analyses revealed Hausas were more than three times more likely to have a low malaria attitude score compared with Igbos (OR, 3.14; 95\% CI, 1.06-9.33; $\mathrm{P}=0.04)$. There were no statistically significant differences in malaria attitude score among Yorubas (OR, 1.85; 95\% CI, $0.62-5.56 ; \mathrm{P}=0.27)$ and other ethnic groups (OR, 1.19; $95 \% \mathrm{CI}$, $0.56-2.54 ; \mathrm{P}=0.65$ ) compared with Igbos. Respondents with less than three sources of messages or training on malaria were almost two times more likely (OR, 1.97; $95 \% \mathrm{CI}, 1.04-3.73 ; \mathrm{P}=0.04)$ to have a low malaria attitude score compared with those having three or more sources (Table 4).

\section{Practices regarding malaria prevention and vaccination}

Most of the respondents $(66 \%, 119$ of 180$)$ sometimes or always slept in insecticide treated nets and 80\% (144 of 180) sometimes or always used anti-mosquito spray. 62\% (112 of 180) of respondents sometimes or always cut bushes and grasses around the house and $58 \%$ ( 105 of 180 ) sometimes or always drained stagnant water near the house (Figure 2). Almost all respondents (98\%; 177 of 180) would allow their child to be immunized with malaria vaccine, 99\% (179 of 180) of respondents are willing to bring their child four times to receive the vaccine and $98 \%(176 / 180)$ would accept malaria vaccination for their child even if given by injec- tion. Most respondents $(84 \%, 151$ of 180$)$ would use other preventive measures in addition to malaria vaccination.

\section{Discussion}

Current advances on malaria vaccines in the fight against malaria, and the pilot implementation of RTS,S being conducted in three sub-Saharan African countries preludes a new phase in the prevention and control of malaria. To ensure the success of this novel intervention, mothers' willingness to allow their child(ren) to accept the RTS,S malaria vaccine, mothers' knowledge, attitude, and acceptance of RTS,S are vital in determining steps that need to be taken to ensure optimal uptake and the success of this intervention. Our study showed general knowledge of malaria and its prevention was high. However, knowledge of malaria vaccine and awareness of RTS,S were very low. Factors, identified from this study, influencing knowledge of preventive measures including vaccines are ethnicity, education, age, employment status and number of malaria messages respondents were exposed to. A lot of effort and funds have been invested into Behavioral Change Communication (BCC) materials by various government and non-

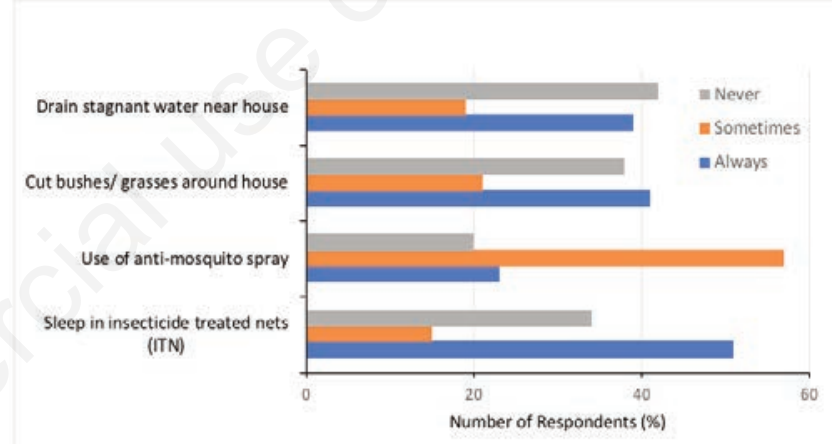

Figure 2. Practices on malaria prevention.

Table 4. Factors associated with Low Malaria Attitude Score ( $<24$ points).

\begin{tabular}{|c|c|c|c|c|}
\hline & $\begin{array}{c}\text { Univariate models } \\
\text { OR }(95 \% \mathrm{CI})\end{array}$ & p & $\begin{array}{l}\text { Multivariable model } \\
\text { OR }(95 \% \mathrm{CI})\end{array}$ & p \\
\hline $\begin{array}{c}\text { Age (years) } \\
\quad \leq 30 \\
>30\end{array}$ & $\begin{array}{c}\text { Reference }(1.00) \\
0.72(0.39-1.32)\end{array}$ & 0.28 & - & - \\
\hline $\begin{array}{c}\text { Ethnicity } \\
\text { Hausa } \\
\text { Igbo } \\
\text { Yoruba } \\
\text { Other }\end{array}$ & $\begin{array}{c}3.04(1.04-8.91) \\
\text { Reference }(1.00) \\
1.63(0.55-4.78) \\
1.06(0.51-2.22)\end{array}$ & $\begin{array}{l}0.04 \\
\\
0.38 \\
0.87\end{array}$ & $\begin{array}{c}3.14(1.06-9.33) \\
\text { Reference }(1.00) \\
1.85(0.62-5.56) \\
1.19(0.56-2.54)\end{array}$ & $\begin{array}{l}0.27 \\
0.65\end{array}$ \\
\hline
\end{tabular}

Education

Pre-secondary

Secondary

Post-secondary

Other

Reference (1.00)

$0.66(0.34-1.25) \quad 0.20$

Employment status

Not employed

Self-employed

Formally employed

$0.98(0.08-11.38)$

0.99

Other

Reference (1.00)

$1.14(0.51-2.52)$

$0.54(0.22-1.34)$

$0.54(0.07-4.31)$

Message or training on malaria

$<3$ sources

$1.99(1.06-3.71)$

$\geq 3$ sources

Reference (1.00)

$1.97(1.04-3.73)$

0.76

0.19

0.03

OR, odds ratio; $\mathrm{Cl}$, confidence interva 
governmental agencies to increase public awareness of malaria at every level. ${ }^{16}$ This could be the reason for the high level of malaria prevention knowledge. This would have to be replicated prior to implementation to attain similar results with RTS,S.

This study found that Hausa and Yoruba mothers were more likely to know three or more preventive measures than Igbos and other tribes. Also, pre-secondary respondents were more likely to know at least 3 preventive measures than post-secondary respondents which means less educated mothers had a better knowledge of malaria prevention. This is not in keeping with previous studies done that suggest that higher education attainment positively influences malaria knowledge. ${ }^{13,17-20}$ The extensive malaria education/training being done at the community level and in health facilities might be a reason for this finding but conducting this research in the other area councils might give a clearer picture.

The study also revealed that receiving three or more malaria messages was found to increase the odds of knowing three or more preventive measures. This indicates consistent, repetitive communication of key malaria messages is effective in improving awareness and would be required to increase knowledge of RTS,S when available for routine immunization use. Studies have shown that regular, consistent exposure to BCC messages improve caregivers use of ITNs (a major malaria preventive measure) ) $^{21-24}$ and is essential for the acceptance of malaria vaccine when available. ${ }^{13,25}$

Furthermore, the study showed that mothers above 30 years were more likely to be aware of malaria vaccines. This could mean that they have had access to more malaria messages, either in the community or health facilities, than the younger respondents. This finding would benefit from further research as a study done in Gwagwalada, showed older age (above 47 years) was associated with poorer knowledge of malaria prevention. ${ }^{19}$ Unemployed respondents were also more likely to know about malaria vaccines than self-employed and formally employed respondents from the results of this study. Although higher wealth index is a factor that determines knowledge of malaria preventive measures, ${ }^{20}$ in this study, being employed did not translate to awareness of the malaria vaccine. This finding could suggest that self-employed and formally employed respondents are not exposed to information on public health advances or malaria messages do not include information on malaria vaccine.

Those who had received less than two malaria messages were more likely to have low attitude scores from this study. This shows that exposure to more malaria messages, irrespective of the source, is necessary to have a positive attitude to malaria prevention. This finding still speaks to the need for constant repetition of malaria messages and novel public health interventions.

Although the Hausas had better knowledge of malaria preventive measures, the knowledge did not translate to a positive attitude towards malaria prevention. This is similar to findings in a study carried out by Singh et al. in Aliero, northern Nigeria that showed knowledge of environmental preventive measures and ownership of ITNs did not necessarily translate to practice of the preventive measures or use of the ITNs. ${ }^{26}$ This was attributed to poor socioeconomic status and low level of formal education within the rural communities. ${ }^{26}$ Igbos with less knowledge of malaria prevention were more likely to have a positive malaria attitude score from this study. With the history of mistrust for western or orthodox medicine among Hausas in Northern Nigeria and the polio vaccination boycott as a precedent, ${ }^{27}$ aggressive advocacy and BCC campaigns will be required to achieve widespread acceptance of RTS,S. This will involve identifying and highlighting positive behaviors to build on, using household, community and political leaders, health facilities and culturally acceptable messages to cultivate the desired attitude and behavior in northern Nigeria

In addition, the study found that almost all respondents were willing to accept the RTS,S malaria vaccine irrespective of route of administration, efficacy of the vaccine (since they were informed of the efficacy before responding to the practice section) and number of doses their child would have to receive. This is a welcome development showing that the immunization program has done a good job of positively influencing the practices of mothers regarding routine immunization and mothers also understand the severity of the disease. A study by Mbengue et al. showed that women who attended antenatal care were more likely to optimally use malaria preventive measures. ${ }^{28}$ Since the women sampled have access to health care facilities and allow their children to be immunized with other routine vaccines, this could account for their willingness to accept the RTS,S malaria vaccine. This might not be the case for mothers in communities who do not have easy access to health care facilities, but this would have to be studied in the future. Also, with the decline in immunizations because of the COVID-19 pandemic, ${ }^{29}$ countries and health communities must identify feasible methods to safely administer vaccines to ensure maximum protection of populations globally.

\section{Conclusions}

A lot has been done regarding educating the public on malaria prevention and the benefits of routine immunization. The findings in this study will prove useful to guide policy makers in decision making when RTS,S is approved for routine use. To achieve adequate knowledge, a good attitude and maximum acceptance of RTS,S, messages on the vaccine and its benefits will have to be consistently communicated to the public through various means prior to implementation. Tailoring messages to different audiences based on age, ethnicity, and education will be required. This will ensure optimal uptake of RTS,S and in conjunction with other preventive interventions, bring us one step closer to eliminating malaria.

\section{References}

1. WHO. Malaria: Key Facts. WHO, 2020 November 20. Accessed 2021 February 1. Available from: h t t p s : / / w w w. w ho. in t/ n e w s - room/fact sheets/detail/malaria\#: : text=Disease $\% 20$ burden,411\%20000 $\% 20$ deaths\%20in\%202018

2. Center for Disease Control and Prevention. Malaria's Impact Worldwide. Center for Disease Control and Prevention, 2021 January 26. Accessed 2021 February 1. Available from: https://www.cdc.gov/malaria/malaria_worldwide/impact.html

3. WHO. Malaria: This year's World malaria report at a glance. WHO, 2019 December 4. Accessed 2021 February 1. Available from: https://www.who.int/news-room/feature-stories/detail/ world-malaria-report-2019

4. WHO. WHO calls for reinvigorated action to fight malaria: Global malaria gains threatened by access gaps, COVID-19 and funding shortfalls. WHO, 2020 November 30. Accessed 2020 Decemeber 2. Available from: https://www.who. int/news/item/30-11-2020-who-calls-for-reinvigorated-actionto-fight-malaria

5. National Malaria Elimination Programme (NMEP), National Population Commission (NPopC), National Bureau of Statistics (NBS), and ICF International. Nigeria Malaria 
Indicator Survey 2015. Abuja, Nigeria, and Rockville, Maryland, USA: NMEP, NPopC, and ICF International, 2016. Accessed 2020 July 17. Available from: https://dhsprogram.com/pubs/pdf/MIS20/MIS20.pdf

6. Nigeria Federal Ministry of Health, National Malaria Elimination Programme. National Strategic plan 2014 - 2020. Abuja. Nigeria. Yaliam Press Ltd, Federal Ministry of Health, 2016 September 4. Accessed 2021 February 1. Available from: https://extranet.who.int/countryplanningcycles/sites/default/fil es/planning_cycle_repository/nigeria/nigeria_national_malaria_strategic_plan.pdf

7. Global technical strategy for malaria 2016-2030, 2021 update. Geneva: World Health Organization; 2021. Licence: CC BYNC-SA 3.0 IGO.

8. United Nations Sustainable Development Goals Knowledge Platform. Sustainable Development Goal 3. United Nations, 2016. Accessed 2020 July 17. Available from: https://sustainabledevelopment.un.org/sdg3

9. WHO. World Malaria Report 2011. WHO, 2011. Accessed 2021 August 25. Available from: https://www.who.int/malaria/world_malaria_report_2011/WMR2011_chapter5.pdf

10. WHO. Immunizations, Vaccines and Biologicals: Malaria Vaccines. WHO, 2018. Accessed 2020 July 17. Available from: https://www.who.int/immunization/research/development/mal aria/en/

11. WHO. Malaria Vaccine: WHO position paper. WHO Weekly epidemiological records. No 4, 2016 January 29, 91, pg 50. Accessed 2021 August 26. Available from: https://www.who.int/wer/2016/WER9104.pdf?ua=1

12. Beliretu I Abdulkadir, Ikeoluwapo O Ajayi. Willingness to accept malaria vaccine among caregivers of under-5 children in Ibadan North Local Government Area, Nigeria. Malaria World Journal 2015;6. Accessed 2020 July 17. Available from: https://malariaworld.org/mwj/2015/research-willingnessaccept-malaria-vaccine-among-caregivers-under-5-childrenibadan-north

13. Chukwuocha UM, Okorie PC, Iwuoha GN, et al. Awareness, perceptions, and intent to comply with the prospective malaria vaccine in parts of South Eastern Nigeria. Malar J 2018;17:187.

14. Federal Capital Development Agency. The Geography of Abuja. FCDA, 2021. Accessed 2021 August 26. Available from: https://fcda.gov.ng/about/the-geography-of-abuja

15. World Population Review. Abuja Population 2021. World Population Review, 2021. Accessed 2021 August 26. Available from: https://worldpopulationreview.com/world-cities/abujapopulation

16. Ankomah A, Adebayo SB, Arogundade ED, et al. The effect of mass media campaign on the use of insecticide-treated bed nets among pregnant women in Nigeria. Malar Res Treat 2014;694863.

17. Kimbi HK, Nkesa SB, Ndamukong-Nyanga JL, et al. Knowledge and perceptions towards malaria prevention among vulnerable groups in the Buea Health District, Cameroon. BMC Public Health 2014; 14:883.

18. Oladimeji KE, Tsoka-Gwegweni JM, Ojewole E, Yunga ST. Knowledge of malaria prevention among pregnant women and non-pregnant mothers of children aged under 5 years in Ibadan, South West Nigeria. Malar J 2019;18:92.

19. Oguntade ES, Shohaimi S, Nallapan M, et.al. Factors influencing malaria knowledge, attitude and practice in Gwagwalada. Int J Sci Healthcare Res 2018;3:168-78.

20. Girum T, Hailemikael G, Wondimu A. Factors affecting prevention and control of malaria among endemic areas of Gurage zone: an implication for malaria elimination in South Ethiopia, 2017. Trop Dis Travel Med Vaccines 2017;3:17.

21. Zalisk K, Herrera S, Inyang U, et al. Caregiver exposure to malaria social and behaviour change messages can improve bed net use among children in an endemic country: secondary analysis of the 2015 Nigeria Malaria Indicator Survey. Malar J 2019;18:121.

22. Bowen HL. Impact of a mass media campaign on bed net use in Cameroon. Malar J 2013;12:36.

23. Owusu Adjah ES, Panayiotou AG. Impact of malaria related messages on insecticide-treated net (ITN) use for malaria prevention in Ghana. Malar J 2014;13:123.

24. Elmosaad YM, Elhadi M, Khan A, et al. Communication for behavioural impact in enhancing utilization of insecticidetreated bed nets among mothers of under-five children in rural North Sudan: an experimental study. Malar J 2016;15:509.

25. Ojakaa DI, Ofware P, Machira YW, et al. Community perceptions of malaria and vaccines in the South Coast and Busia regions of Kenya. Malar J 2011;10:147.

26. Singh R, Musa J, Singh S, Ebere UV. Knowledge, attitude and practices on malaria among the rural communities in Aliero, northern Nigeria. J Family Med Prim Care 2014;3:39-44.

27. Jegede AS. What led to the Nigerian boycott of the polio vaccination campaign? PLoS Med 2007;4:e73.

28. Mbengue MAS, Bei AK, Mboup A, et al. Factors influencing the use of malaria prevention strategies by women in Senegal: a cross-sectional study. Malar J 2017;16:470.

29. WHO. WHO and UNICEF warn of a decline in vaccinations during COVID-19. WHO. 2020 July 15. Accessed 2020 August 4. Available from: https://www.who.int/newsroom/detail/15-07-2020-who-and-unicef-warn-of-a-declinein-vaccinations-during-covid-19 